\title{
Case study: Editing Technique of Video of Batik Making Process as Media of Entrepreneurial Learning
}

\author{
Ninik Sudarwati ${ }^{1}$, Agus Prianto ${ }^{2}$, Rukminingsih ${ }^{3}$ \\ \{ninik.stkipjb@gmail.com ${ }^{1}$, pimpinan1@yahoo.co.id ${ }^{2}$, rukminingsih19@yahoo.co.id ${ }^{3}$ \} \\ STKIP PGRI Jombang, East Java, Indonesia ${ }^{123}$

\begin{abstract}
This study aims to describe the case study about editing technique of film of batik making process as media in entrepreneurial learning. Research method employed was qualitative research. Video editing was conducted using wondershare filmora app. The video editing technique included importing files, edit the title, create clear and short text design, add text to the video, edit text, cut and organize a file, add back sound into the edited video, export the video which has been edited. The video editing process was conducted in accordance with the requirements in video editing. Further research should be evaluated and validated by the experts in video editing and multimedia to improve the product.
\end{abstract}

Keywords: video editing technique, learning media, entrepreneurial learning.

\section{Introduction}

Editing is an important part of making any film or video. As the most essence of video is editing. It's the combination of what can be extraordinary images of people during emotional moments, or images in a general sense. The field of video editing has come a long way in the past few years. What earlier was a domain of creative professionals with extensive know-how in the cutting-edge software is now crowded with YouTube stars and home video professionals who can create engaging and incisive video content while using relatively simple tools. At the same time, the future of video editing still lies in the hands of professional film and video editors who are leveraging state-of-the-art technology to push the realms of what is possible. Today, video editing trends and their applications are benefiting multiple industries such as film, broadcasting, advertising, marketing, etc

The use of the different audio visual techniques in communication and expression of ideas has been widely regarded as an important and significant evolution of the different techniques used for communication that emerged from the use of print medium and incorporation of multimedia. Communication has always been an important part of human existence and throughout the history of mankind; the same has seen a transformation from mere papyrus sheets to the incorporation of the elements of sight and sound [1]. The opinion of experts on the transformation on the use of visual communication is diverse, but all of them are believed to be in affirmation with the fact that the use of different audio visual techniques in communication is considered to be the most effective and efficient by senders and receivers alike [2]. The reason behind the same being the fact that the incorporation of the different audio visual formats helps in the presentation of the communication in a most concise manner, yet again enabling the sender to create a long lasting impression on the mind of the receivers [3]

Video provide an overview of current short-term and long-term trends regarding how technology is affecting Higher Education and consider the integration of online, hybrid and collaborative learning to be a fast trend, driving changes in Higher Education over the next one to two years [4]. The increased use of video as a teaching medium is encroaching onto traditional face-to-face teaching in Higher Education. This affects lecturers, students, Universities and Colleges and there is a need to bridge the gap in digital competencies [5]

ICCSET 2018, October 25-26, Kudus, Indonesia

Copyright (C) 2018 EAI

DOI 10.4108/eai.24-10-2018.2280586 
The learning process can be described as a dialogue (iterative conversation) between the lecturer and the student, that takes place at a conceptual and applied level [6][7]. For a detailed discussion and analysis of the learning process, technology impacting education and social and educational developments [6]. Based on the explanation above, it can be concluded that Editing of film or video material is an essential part of any audio-visual production. Without the process of removing, adding and manipulating source material, all film and video would have to be shot in sequence and without mistakes

Entrepreneurial education is an activity or process of forming entrepreneurial attitude that must be trained both theoretically and practically until students are skilled in managing the business, both theoretically and practically. Entrepreneurship education can improve entrepreneurial skill in entrepreneurship. Entrepreneurial learning can upgrade the skills in specific job expertise, increase financial income, and encourage learners to be self-employed entrepreneurs [8]. Entrepreneurship education can improve skills in entrepreneurship, especially if the education is supported by the applicative material and demands the learners to practice themselves. This is in accordance with [9] that learning activities providing applicative materials and space for learners to practice can improve entrepreneurial learning. The results of preliminary study in college indicate issues in entrepreneurial learning. The main issue is the limited time for entrepreneurial learning, which is only conducted for 150 minutes per week. In that period of time, the teacher is required to deliver the material as well as to form entrepreneurial skills in students. The establishment of entrepreneurial skills requires a long process and time. Moreover, the real example of a successful entrepreneur and the time spent in entrepreneurial practice by applying management strategies is quite limited. Enhancing the management knowledge of small businessmen can be done by learning theories and through entrepreneurial learning practice [10]. Instructional media is required to succeed learning process; it is in accordance with [11] that one of the factors that can influence the success of learning is the use of learning media. The statistical analysis of post-test results of experimental group and control group indicated significant difference; it was concluded that interactive multimedia is an effective learning material in the learning activity, especially for listening skill. The students can interact with the characters, various emotions and actions of the actors that appear in audiovisual settings. Film illustrates the potential of scientific audiovisual language, which is commonly used as a medium for teaching. The audience (students) can learn the values of information and knowledge provided in the film. It happens because of the integration between reality faced by the individuals and the environment. Audiovisual language is a variable that determines the effectiveness of film, which is useful for improving the learning and teaching process.

The purpose of this study is to describe the case study about editing technique of film of batik making process as media in entrepreneurial learning.

\section{Research Method}

This research is a qualitative research, which is aimed to describe and analyze phenomena, events, social activities, beliefs, perceptions and the thoughts of people, both as individuals and as a group. Descriptive research is intended to describe a circumstance or phenomena as it is on a single object [12]. This study aims to describe a phenomenon or circumstance based on real observations.

This research describes the editing process of video titled "batik making process as media in entrepreneurial learning". The document of the record on making process of Batik is as a source of data. This video was made in 2018. The scenario of this video was written by Ninik 
Sudarwati. The duration of this video is 15 minutes. The data source of video editing was the primary data in the form of shots, which are parts of very long series of images; it was only recorded with one take. In this stage, the shots that have been taken were selected, processed, and assembled, so that they become a unity. Image editor is required to be able to tell the story behind the images that will be constructed.

Arranging shots means connecting one image and another and evoking audience emotion. This study employed "continuity editing" with "matching the look shot", connecting one shot and another, with respect to shape and space for continuity or match between one shot and another, in order to make the audience feel comfortable or uninterrupted. The editing method used was "continuity cutting", which is the most commonly used method because there is no binding rule except match on action/match on cut, meaning that the connection is made in such a way that the audience feel comfortable and feel interrupted by the cutting.

\section{Results}

Video editing was conducted using wondershare filmora application. It has features that can make the video look attractive to the audience. Filmora app has more editing effects. It performs well and is easy to use, especially for beginners

There are 4 menu options you can use to create videos on Wondershare Filmora:

Full Feature mode

In this option, you can use all features available in this application, either video editing, sound or video cropping.

Easy Mode

It is an easy feature provided in this application. There are parts that are not complicated for video editing you can use this application.

Instant Cutter

This is provided for cutting video with simple features.

Action Cam Tool

This feature is provided for video editing related to image brightness, video speed and more.

The steps in Editing the Batik Process Video as Learning Media are as follows

The first step is import files about the process of making batik into Filmora Application.

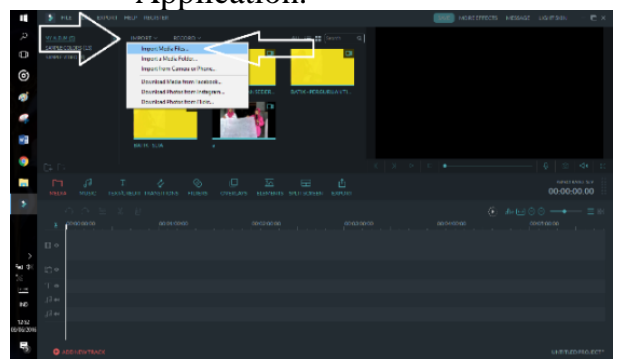

Fig. 1. Import files.

Move the cursor to the file to be edited, and then the middle (+) sign will appear and click on it to put it into the project (Track). You can also drag the File into the Track. 


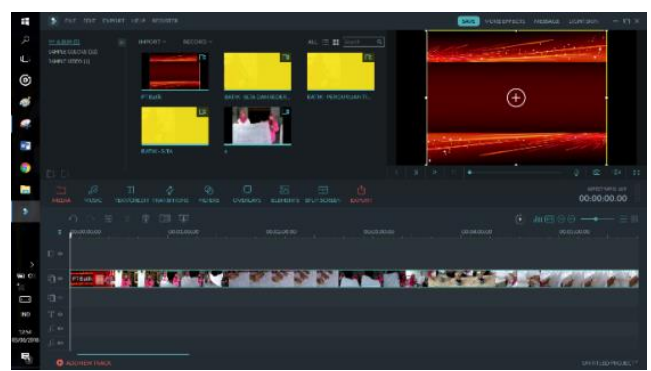

Fig. 2. Edit the file.

Layer of video, text, and audio/sound is a place to put the file to be edited.

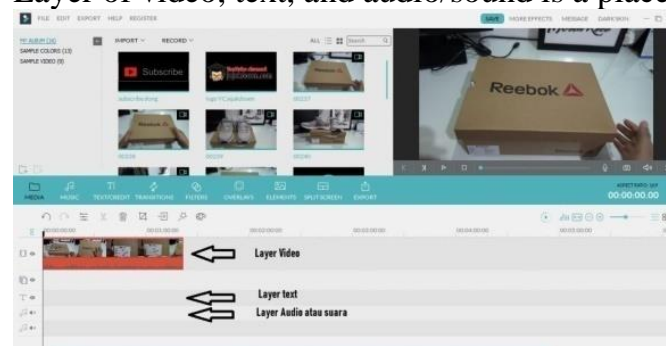

Fig. 3. Place to put the file to be edited.

Text/Credit section is used to add text into the video to be edited by moving the cursor to Design Text that appears. Symbol (+) will appear in the middle and click the button to enter it into the project (Track). You can also drag the file into Track.

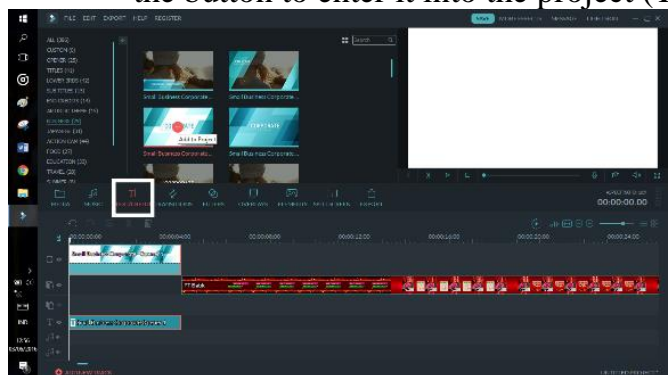

Fig. 4. Find the type of text design.

To edit Text, double click on Text which is in Track (which have been added earlier/drag). Then, a new window will appear on the left of Video. Fill in the text in the window that appears and also edit the size of text, font type, color, and others. There are 3 kinds of text type, namely Text Opening, Text Ending and Text Explanation or Additional Description. To make readers understand what is conveyed, the text color should not be aligned with background color; the text will be unclear and difficult to read. 


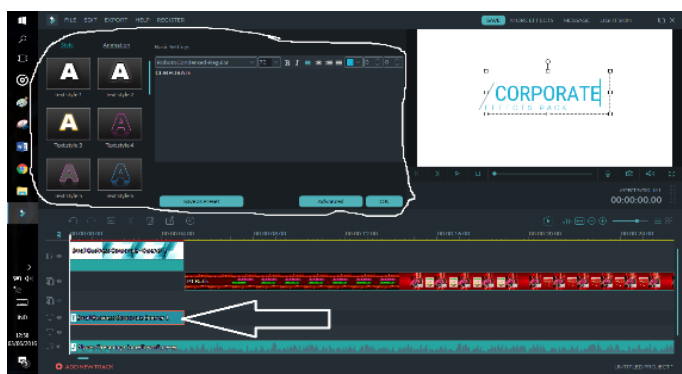

Fig. 5. Edit the text.

The function of "split" button is to cut a file into 2 parts.

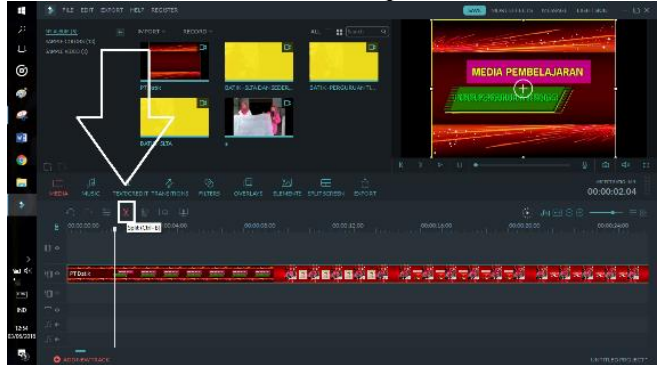

Fig. 6. Cut the file.

If a video is split, then the video will be cut into 2 parts. Among those parts, we can insert other videos or also delete those videos. I often use this function to insert or delete parts of video and replace them with other parts.

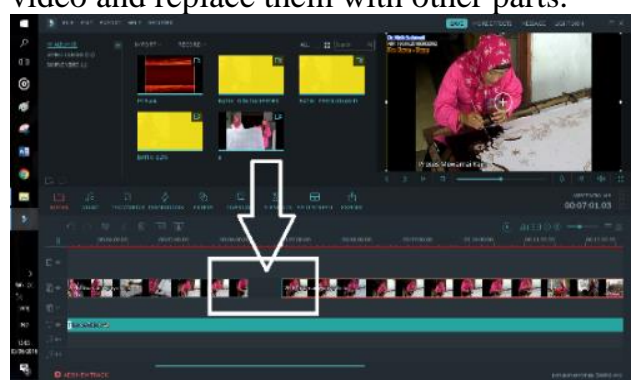

Fig. 7. Example of cutting file.

Music Section is used to add back sounds into the video edited. Select the music that has been provided and drag it into the Track. Back sound is used to accompany the video without affecting the voice of the speaker. Back sound will also make the video that we make more lively and not monotonous or boring. 


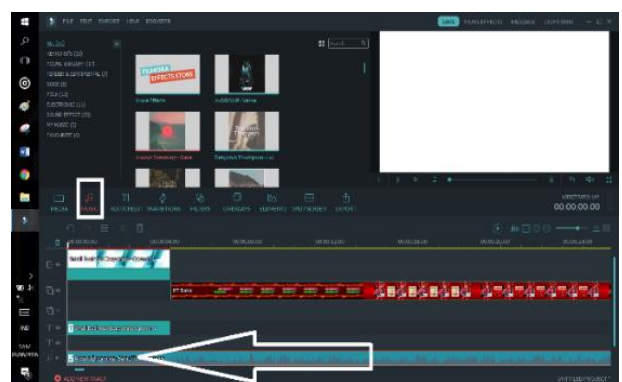

Fig. 8. Adding back sound into the video edited. After the video is finished, then export the video. It is done to unite various files into a single file in the form of video format.

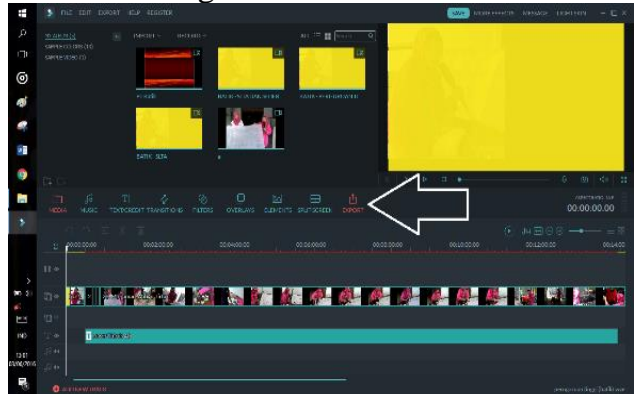

Fig. 9. Export the video.

Once "Export" button is clicked, a new window that is used to save the video, video title, and type of files you want to make (MP4, GIF, AVI, etc.) will appear. In order that the video has a high resolution, then click "Setting", set the resolution into 1920 x 1080 and select "Best" quality. To see the results of the video editing process, you can visit YouTube with the following link: https://youtu.be/Hdk6rKe4r1I

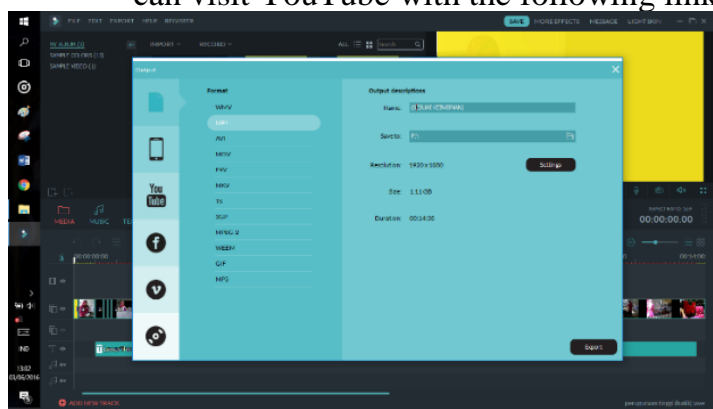

Fig. 10. New window to save the edited video.

The figure above is a new window for saving the edited video in the selected form, including MP4, GIF, AVI, etc. Therefore, video editing technique includes importing files, editing titles, finding text design, adding text to video, editing text, cropping a file, adding back sound into the edited video, exporting the edited video, and saving the edited video, video title, and the preferred file type. The video of the steps of batik making process is matching and continuous. 


\section{Discussion}

Image editing of video of batik making process was done in accordance with the steps of batik. Image editing was done to obtain various effects of information, to help storytelling, to provoke ideas, to motivate the learning activity of students, to attract audience's attention and to help them remember it; therefore, the main task of video editor is to compose the shooting results and to form a story [1] and [2]. Shot arrangement is capable of connecting one image with another and evoking audience emotion. Shot arrangement on the editing process must conform to the information to be presented in the film .

The editing process has been carried out continuously and in accordance with the steps of batik process, among others: edit the title, determine the text design appropriate for learning media, add the text into the video on each step in making batik as a brief guide, edit the text to be more practical and give clear meaning, cut out unnecessary and boring files, add soft and slow instrumental back sound to the video edited which is appropriate with the nuance of batik, export the edited video and save it. This is in line with the opinion of that "Continuity Editing" aims to make the audience feel comfortable or not disturbed by the ambiguity of space and time and create continuity or match between shots, so that one shot is connected to the next shot by considering shape and space as well [6] and [7].

The video of batik making process is a video that serves as entrepreneurial learning media. Batik products are a work of creativity. This is in accordance with [13] that the point of entrepreneurship is the imagination, creativity, novelty and sensitivity to develop new products or services.

Editing Technique of Video as a learning media is different from editing video as non learning media. Editing Video of batik making process for learning media has some details as the following:

It has text explaining in each step for making process of Batik.

It has learning competence in the process of editing process of making Batik.

It has explanation in each step for making process of Batik.

Some requirements which are needed to edit the video of Batik making process as the following:

Proven work experience as a video editor

Solid experience with digital technology and editing software packages (e.g. Avid Media Composer, Lightworks, Premiere, After Effects and Final Cut)

Demonstrable video editing ability with a strong portfolio

Thorough knowledge of timing, motivation and continuiting

Creative mind and storytelling skills

Thus, the video of batik making process has been edited such a way that it becomes continuous, harmonious and interesting for the audience. The video is an audiovisual-based media in entrepreneurial learning that is practical and provided with clear instructions.

\section{Conclusion}

The video of making batik process as media in entrepreneurship learning is interactive as it is equipped with a brief written explanation on each step of the process of batik. Editing activities start from importing files, edit the title (set contrasting and clear color), create clear and short text design, add text to the video (in each batik process), edit text, cut and organize a file, add back sound into the edited video (music appropriate for the activity), export the video 
which has been edited. The video editing process is in accordance with editing requirements. Further research requires evaluation and validation of the video as media in entrepreneurial learning from the experts in video editing and multimedia experts to improve the product.

\section{References}

[1] G. Branston and R. Stafford, The media student's book. London: Routledge, 2010.

[2] S. Cunningham and G. Turner, The media and communications in Australia. Sydney: Allen \& Unwin, 2010.

[3] G. Chandler, Cut by Cut: Editing Your Film or Video. Studio City, CA: Michael Wiese, 2004.

[4] L. Johnson, S. Adams Becker, V. Estrada, and A. Freeman, "NMC Horizon Report: 2014 Higher Education Edition," Austin, Texas, 2014.

[5] F. W. Jacobs, "Slagvaardig met ICT: Ontwerpprincipes voor leeromgevingen die professionele digitale competenties van hbo-studenten versterken," Zuyd Hogeschool, 2013.

[6] J. Fransen, Instrumentatie van beteknisvolle interacties. den haag: Inhholland, 2015.

[7] D. Laurillard, Rethinking university teaching: A framework for the effective use of learning technologies (2nd ed.), 2nd ed. Abingdon: RoutledgeFalmer, 2002.

[8] N. A. Bashir and K. Jehanzeb, "Training and Development Program and Its Benefits to Employee and Organization: A Conceptual Study,” Eur. J. Bus. Manag., pp. 243-252, 2013.

[9] E. Lomsdaine and M. Bink, "Teaching Entrepreneurship to Engineers," Am. Soc. Eng. Educ., 2003.

[10] A. R. C. Omar, S. Ishak, and M. R. Rashid, "Consulting - based Entrepreneurial/Business Learning: Malaysia Experience," African J. Bus. Manag., vol. 4, no. 12, pp. 2508-2513, 2010.

[11] A. Arroio, "Context based learning: A role for cinema in science education," Sci. Educ. Int., vol. 21, no. 3, pp. 131-143, 2010.

[12] K. Denzin, Norman and S. Lincoln, Yvonna, Handbook of Qualitative Research. New Delhi: Sage Publication, 2009.

[13] R. A. Buchholz, "The Spirit of Entrepreneurship and The Qualities of Moral Decision Making: Toward a Unifying Framework,” J. Bus. Ethics, pp. 307-315, 2005. 